Accepted for publication in the "International Journal of Psychophysiology"

Note: This is an uncorrected version of an author's manuscript accepted for publication.

Copyediting, typesetting, and review of the resulting proofs will be undertaken on this manuscript before final publication. During production and pre-press, errors may be discovered that could affect the content.

\title{
The cognitive mechanisms underlying deception: An event-related
}

\section{potential study}

Kristina Suchotzki ${ }^{1}$, Geert Crombez ${ }^{1}$, Fren T. Y. Smulders ${ }^{2}$, Ewout Meijer ${ }^{2}$, and Bruno Verschuere $^{3,1,2,}$

${ }^{1}$ Department of Experimental-Clinical and Health Psychology, Ghent University, Henri Dunantlaan 2, 9000 Ghent, Belgium

${ }^{2}$ Faculty of Psychology and Neuroscience, Maastricht University, Universiteitssingel 5, 6200 MD Maastricht, The Netherlands

${ }^{3}$ Department of Clinical Psychology, University of Amsterdam, Weesperplein 4, 1018 XA Amsterdam, The Netherlands

\section{Corresponding author:}

Kristina Suchotzki

Department of Experimental Clinical and Health Psychology

Ghent University

Henri Dunantlaan 2

B-9000 Ghent, Belgium

Phone: +32 (0)9 2649446

Kristina.Suchotzki@UGent.be 


\begin{abstract}
The cognitive view on deception proposes that lying comes with a cognitive cost. This view is supported by the finding that lying typically takes longer than truth telling. Event-related potentials (ERPs) provide a means to unravel the cognitive processes underlying this cost. Using a mock-crime design, the current study $(n=20)$ investigated the effects of deception on the Contingent Negative Variation (CNV), the Lateralized Readiness Potential (LRP), the Correct Response Negativity (CRN), and the stimulus-locked N200 and P300 components. In line with previous research, lying resulted in more errors, longer reaction times (RTs) and longer RT standard deviations compared to truthful responses. A marginally significant effect suggested a stronger CNV for the anticipation of lying compared to the anticipation of truth telling. There were no significant deception effects on the stimulus- and the response-locked LRPs. Unexpectedly, we found a significantly larger CRN for truth telling compared to lying. Additional analyses revealed an enhanced N200 and a decreased P300 for lying compared to truth telling. Our results support the cognitive load hypothesis for lying, yet are mixed regarding the response conflict hypothesis. Results are discussed with regard to the specific characteristics of our design and their theoretical and applied implications.
\end{abstract}

Keywords: Deception; ERP; Cognitive load; LRP; CNV; CRN 


\section{Introduction}

For a long time, researchers and practitioners have relied on the assumption that deception is accompanied by heightened emotional arousal. Yet, the robustness and specificity of the link between deception and arousal have been criticized (Lykken, 1998; National Research Council, 2003; Vrij et al., 2006; Vrij et al., 2011). Therefore, in the last decade, there has been renewed interest in a cognitive approach to deception. The central idea is that lying is cognitively more demanding than truth telling (DePaulo et al., 2003; Vrij et al., 2006; Zuckerman et al., 1981). More specifically, it has been reasoned that the formulation of a credible lie requires that the truth is kept active in working memory. The activated truth response then conflicts with the to-be-given lie response, requiring response monitoring and inhibition processes (Christ et al., 2009; Seymour \& Schumacher, 2009; Spence et al., 2001; Verschuere \& De Houwer, 2011; Walczyk et al., 2003). Finally, task switching enables changing between truthful and deceptive responses. So far, several lines of research support this cognitive view of deception (Christ et al., 2009; Vrij et al., 2011).

Event-related potentials (ERPs) provide an attractive means to study the cognitive processes involved in deception more closely. Of specific relevance in this context are studies using the Contingent Negative Variation (CNV; Brunia et al., 2012; Walter et al., 1964). The CNV is a slow negative-going brain potential, evolving after a cue and before an imperative stimulus. It is thought to reflect processes of anticipation and response preparation. Using different paradigms and stimuli, three deception studies found an enhanced CNV for lying compared to truth telling (Dong \& Wu, 2010; Fang et al., 2003; Sun et al., 2011). In the study by Fang et al. (2003), participants were instructed to deceptively deny knowledge of familiar target faces, and to truthfully admit knowledge of other familiar faces and deny knowledge of unknown faces. In the study by Sun et al. (2011), participants chose for their own financial gain whether to truthfully or deceptively evaluate banknotes as genuine. Dong and $\mathrm{Wu}$ (2010) instructed participants to truthfully or deceptively indicate the attractiveness of faces. In line with the cognitive theory of deception, authors of all three studies interpreted these CNV deception effects as indication for a higher effortful involvement and higher cognitive load for lying compared to truth telling. It should, however, be noticed that in the three studies, the CNV was measured after participants had already been given all stimulus information necessary to prepare their correct deceptive responses. As a consequence, the $\mathrm{CNV}$ in these studies did not purely measure the anticipation of lying and truth telling, but 
this anticipation was already combined with stimulus processing and (motor) preparation of the correct response.

Another component that has attracted attention in the context of lying is the Correct Response Negativity (CRN; Vidal et al., 2003; Vidal et al., 2000). The CRN is closely related to the error-related negativity (ERN), a negative ERP component at fronto-central electrodes along the midline, peaking 0-100 ms after an incorrect response (Falkenstein et al., 1991; Gehring et al., 1993). Although initially attributed to error-detection (e.g., Coles et al., 2001), the discovery of a similar - albeit smaller - negative peak after correct responses challenged this view and led to the proposal that both components serve a more general conflict-monitoring function (Botvinick et al., 2001). Within deception research, it has been found that deceptive compared to truthful responding elicited a stronger CRN (also referred to as Medio-Frontal Negativity), which had been attributed to stronger response-monitoring demands for deceptive responses (Dong et al., 2010; Johnson et al., 2004, 2005; Johnson et al., 2008; Kireev et al., 2008). Johnson et al. (2004; 2005) employed an old/new word paradigm, in which participants had to sometimes correctly and sometimes incorrectly indicate recognition of old words. Johnson et al. (2008) instructed participants to lie about their attitudes towards well-known persons. Dong et al. (2010) instructed participants to make honest or deceptive evaluations of the attractiveness of face stimuli. However, although those studies found and replicated the effect with different paradigms and stimuli, none of the four studies created a more realistic deception situation in which participants were actually motivated to lie successfully. The only study that used an incentive for successful lying was a study by Kireev et al. (2008), in which participants responded truthfully or deceitfully (i.e., to indicate the directions of arrows with button presses either correctly or incorrectly) with the purpose to win money by 'deceiving' a computer. Yet, the sample size of their study was relatively small ( $n=13$; Simmons et al., 2011), and - as in the CNV study of Sun et al. (2011) - participants could freely choose between truth telling and lying, which made it impossible to differentiate between intentional lies and behavioral errors.

The aim of the present study was to replicate effects of previous studies, yet with a paradigm that enables maximal experimental control. More specifically, we used a Sheffield Lie Test (Spence et al., 2001; based on the Differentiation of Deception paradigm by Furedy et al., 1988). Unlike in many other deception paradigms (e.g., CQT; Reid, 1947), the experimental and control conditions here only differ in the crucial variable: Deception. Originally combined with recordings of the autonomic nervous system, the paradigm has 
more recently also been used to measure neural and behavioral effects of deceptive responding (Spence et al., 2001). In the Sheffield Lie Test, participants are presented with stimuli, as for instance simple yes/no questions, and instructed to lie or tell the truth depending upon a color cue. By lying and telling the truth on the same set of questions, each stimulus forms its own control. In line with the view that lying is cognitively more demanding than truth telling, behavioral studies using this paradigm have consistently shown that lying is more error-prone than truth telling and associated with longer and more variable response latencies (Debey et al., 2012; Farrow et al., 2010; Fullam et al., 2009; Hu et al., 2012; Van Bockstaele et al., 2012; Verschuere et al., 2011). In our version of the Sheffield Lie Test, participants gave speeded yes/no responses to mock-crime and control questions using left and right button presses. A question was presented (e.g., "Did you steal a...") for $2000 \mathrm{~ms}$, followed by a truth (T) or lie (L) cue. The cue was replaced after $1500 \mathrm{~ms}$ by a keyword (e.g., “cd-rom?"), allowing participants to respond. This setup allowed us to measure the CNV during the pure anticipation of lying and truth telling, without the interference of processing of the crucial stimuli or (motor) preparation of the correct response.

The setup of the current study also allowed us to measure the CRN after deceptive and truthful responses. It also allowed us to investigate another ERP component that has not been investigated in the context of deception before: The Lateralized Readiness Potential (LRP; for a review see Smulders \& Miller, 2012). The LRP is a negative potential over the primary motor cortex (M1), contralateral to the responding hand that starts before the response is emitted. It reflects the time at which one hand is activated over the other in the preparation of a unimanual overt response. Crucially, this allows tracking covert response-competition processes before the overt motor response has occurred. In many 'conflict' paradigms (e.g. Gratton et al., 1988), initial activation of the incorrect response was shown to precede later correct response activation. Whereas the stimulus-locked LRP indicates the duration of processes occurring before the start of the correct response-activation, including stimulusprocessing and response competition, the response-locked LRP interval indicates the duration of processes that occur after activation of the correct response. Based on the idea that during lying, the truth is initially activated and conflicts with the lie, we expected the stimulus-locked LRP to reveal an initial activation of the (incorrect) truthful response during lying.

Following up on the suggestion of a reviewer, we further extended our analyses and included two additional components: the N200 and the P300. The N200 is a negative-going component that occurs around $200-350 \mathrm{~ms}$ post-stimulus and is found primarily over 
anterior scalp sites. It has been hypothesized to be involved in executive cognitive control, and more specifically in conflict detection (Folstein \& Van Petten, 2008; Van Veen \& Carter, 2002). The P300 component (Sutton et al., 1965) occurs around $300-800$ ms post-stimulus and is found mostly over posterior scalp sites. It has been mostly studied in oddball paradigms, in which it is thought to reflect increased attention towards rare, novel or salient stimuli (Polich, 2011). It has also been shown to be influenced by cognitive load (Isreal et al., 1980a,b; Kramer et al., 1985; Wickens et al., 1983). A previous study of Hu et al. (2011) used a slightly different variant of the Sheffield Lie Test, in which participants indicated recognition of self- and other-related information equally often truthfully and deceptively. The authors observed an increased fronto-central N200, and a decreased fronto-central P300 for lying compared to truth telling, which they interpreted as indication that compared to truth telling, lying comes with increased response conflict and enhanced cognitive load, respectively (see also Johnson et al., 2003, 2005; Wu et al., 2009). In our extra analyses, we examined whether these results replicate in our data.

In sum, in the current study, we aimed at replicating and extending previous ERP deception results with a deception paradigm that guarantees maximal experimental control. In order to create a situation that mimics forensic contexts, we used a mock-crime procedure in which participants performed one mock-crime and planned another mock-crime (i.e., criminal intention). The latter was implemented to contribute to an emerging research line that investigates whether classical deception findings can be extended from deception about already performed acts (e.g., crimes) to deception about merely planned ones (e.g., Clemens et al., 2011; Granhag \& Knieps, 2011; Meijer et al., 2010; Meixner \& Rosenfeld, 2011; Noordraven \& Verschuere, 2013). To increase motivation, participants were promised an extra financial reward for hiding their true acts. Based on previous research and the cognitive processes that were proposed to underlie deception, we expected the following: (1) a more negative CNV after lie cues compared to truth cues, (2) an initial deflection of the stimuluslocked LRP in the direction of the incorrect truth response in lie trials and no such deflection in truth trials, (3) a stronger CRN after lie responses compared to truth responses, and (4) an increased N200 and a decreased P300 for lying compared to truth telling.

\section{Method}

\section{1. Participants}


Twenty students (15 female) from Maastricht University participated for a monetary reward (30€). All participants were right-handed, free of neurological disorders, and reported normal or corrected-to-normal vision. All gave written informed consent. No participant exceeded the general mean error rate plus $2.5 S D$ 's $(M=12.94, S D=9.36)$. The mean age of the participants was $21.65(S D=3.15$, range from $18-28)$.

\section{2. Mock crime procedure}

Participants were informed that they had to plan and commit two mock crimes. For the first mock crime, participants were instructed to go to the second floor of the building, find the kitchen and steal a CD-ROM, which was left on the microwave. For the second mock crime, participants were instructed to go to the third floor, find the computer room and steal a USB-Stick, which was left on the scanner. The order of the two mock crimes was counterbalanced across participants. After receiving the instructions for the first mock crime, participants were given some time to "plan" the crime. Planning included thinking about how they would perform the crime and writing down the most important steps. They then executed the first crime, returned to the laboratory, and received the instructions for the second crime. When planning of the second crime was completed and participants were about to leave the laboratory, they were informed that there was a slight change in the procedure and that they had to complete a lie detection test first, before executing the second crime. During this test, stimuli relating to both crimes were presented. Participants did not execute the second crime, but were debriefed after the test. Thus, all participants planned two mock crimes, but performed only one.

Instructions for both crimes were delivered in an envelope and participants were (incorrectly) told that the experimenter did not know which mock crimes they would commit. They were explained that the purpose of the experiment was to derive from their data which mock crime they had committed and which they had planned. They were also told that if they succeeded in hiding this, they would receive an extra reward of 5 Euro. At the end of the experiment, everyone was debriefed and received the extra reward, independent of performance.

\section{3. Experimental design and stimuli}

The experimental task was presented with E-prime 2.0, with stimuli presented in Arial font in the center of a black 17-inch computer screen. As stimuli, four different categories of 
crime-related questions were used, with 20 different questions in each category. The first two categories consisted of questions concerning (1) the enacted mock crime (e.g., "Did you steal a cd-rom?”), and (2) the planned mock crime (e.g., “Are you planning to steal a usb stick?”). To avoid that the truth answer was always affirmative, we also used control questions concerning two mock crimes they (3) did not commit (e.g., "Did you steal a bag?") and (4) did not plan to commit (e.g., “Are you planning to steal a key?”).

The task was an adaptation of the Sheffield Lie Test (Spence et al., 2001). Participants gave speeded yes/no responses to all questions using left and right button presses. The crucial changes of the paradigm include the presentation of the sentences in two parts to enable faster responding, the use of a Lie/Truth cue before the actual stimulus as a partially informative cue, and the implementation of a response deadline to motivate participants to respond as fast as possible. Unlike many studies using the Sheffield Lie Test, we did not present yes/no response labels on the screen. This was done to avoid systematic eye movements that may confound LRP effects (see Smulders \& Miller, 2012). Our experimental design is depicted in Figure 1.

\section{- INSERT FIGURE 1 ABOUT HERE -}

Initially, the first part of a question was presented (e.g., "Did you steal a...") for 2000 ms, followed by a truth (T) or lie (L) cue. The cue was replaced after $1500 \mathrm{~ms}$ by a keyword (e.g., "cd-rom"), allowing participants to respond. The response deadline was set to $2000 \mathrm{~ms}$. If participants did not respond before the deadline, the words "Too late" were presented on the screen for $700 \mathrm{~ms}$. If participants responded in time, a black screen was presented for 700 ms. After that, the inter trial interval varied randomly between 300 and $900 \mathrm{~ms}$. Note that although the cue is partially informative in the sense that it gives information about the task the participant has to perform (lying or truth telling), it does not deliver any information about the hand with which the participant has to respond (to avoid early lateralized motor processes).

\section{4. Data acquisition, reduction and analysis}

Error rates, RTs, and the standard deviation of the RTs were used as behavioral indices. RTs were measured from the onset of the keyword until the response was made. Responses exceeding the response deadline were discarded (2.29\%). For the RT analysis, errors were discarded. To reduce the impact of outlying values, reaction times more than 2.5 
standard deviations from the mean per subject and condition (Ratcliff, 1993) were also removed from the RT analysis (2.13\% of all trials with correct responses).

The EEG was continuously recorded from $12 \mathrm{Ag} / \mathrm{AgCl}$ electrodes located at standard electrode positions (Fz, FCz, Cz, Pz, Oz, FC1, FC2, FC3, FC4, C3, C4, and the right mastoid, A2) of the International 10-20 system (Jasper, 1958), with a sample rate of $200 \mathrm{~Hz}$. All leads were online referenced to the left mastoid (A1). Horizontal electrooculograms (HEOGs) were recorded from F9 and F10 and vertical electrooculograms (VEOGs) from Fp2 and below the right eye. AFz served as ground electrode. Electrode impedances were kept below $5 \mathrm{k} \Omega$. The signal was filtered online with a 0.016 high pass filter. All leads were offline re-referenced to an average of A1 and A2. ERP's of interest were computed using the following sequence: (1) applying a bandpass filter $(0.016-35 \mathrm{~Hz})$ to the continuous data (EEG channels), (2) -1800 / +2500 ms segmentation around the keyword, thereby also including the cue and a minimum of $+500 \mathrm{~ms}$ after the response; including only correct responses within the response deadline, RT < $2000 \mathrm{~ms}$ ), (3) baseline correction over whole epoch, (4) ocular artifact correction using the Gratton-Coles procedure (Gratton et al., 1983), (5) baseline correction over whole epoch, (6) artifact rejection (all trials containing voltage steps exceeding $50 \mu \mathrm{V} / \mathrm{ms}$ and a maximal difference of values of $200 \mu \mathrm{V}$ in intervals of $1000 \mathrm{~ms}$ ), (7a) for the CNV: baseline correction (-200 ms to cue), segmentation $-200 /+1500$ around the cue and average trials for each experimental condition separately; (7b) for the S-locked LRP: baseline correction (-200 to keyword), segmentation $-200 \mathrm{~ms} /+2000 \mathrm{~ms}$ around the keyword and average trials for each experimental condition and left and right hand responses separately; (7c) for the CRN: segmentation $-200 \mathrm{~ms} /+1000 \mathrm{~ms}$ around the response, baseline correction $(-200 \mathrm{~ms}$ to response), segmentation and average trials for each experimental condition separately; (7d) for the N200 and P300: baseline correction (-200 to keyword), segmentation -200 ms / +2000 $\mathrm{ms}$ around the keyword and average trials for each experimental condition and left and right hand responses separately.

For each of the components, the mean activity within the respective crucial time window at the respective electrodes was calculated. For the CNV, the mean activity at Fz, $\mathrm{FCz}$, and $\mathrm{Cz}$ was calculated during the 1000 to $1500 \mathrm{~ms}$ interval after the onset of the cue. The LRP was computed for the electrodes C3 and C4, using the following formula of Coles (1989): [(C4(t) - C3(t))left hand + (C3(t) - C4(t))right hand ] / 2, with C3(t) and C4(t) denoting the digitized scalp potentials at $\mathrm{C} 3$ and $\mathrm{C} 4$ for multiple time points. For the stimuluslocked LRP, the mean activity during the 300 to $600 \mathrm{~ms}$ interval and the 600 to $900 \mathrm{~ms}$ 
interval after the onset of the stimulus was calculated. For the CRN, the mean activity during the 0 to $100 \mathrm{~ms}$ interval after the correct response was calculated at Fz, FCz, Cz, and Pz. For the N200, the mean activity at $\mathrm{Fz}, \mathrm{FCz}$, and $\mathrm{Cz}$ was calculated during the 250 to $350 \mathrm{~ms}$ interval after the onset of the keyword. For the P300, the mean activity at $\mathrm{Fz}, \mathrm{FCz}, \mathrm{Cz}, \mathrm{Pz}$, and $\mathrm{Oz}$ was calculated during the 350 to $800 \mathrm{~ms}$ interval after the onset of the keyword. The selection of electrodes and crucial time intervals was based on converging results in previous research as well as on visual inspection of the current data.

To circumvent the potentially problematic sphericity assumption of univariate repeated measures analyses, multivariate analyses were used. 2 (Deception: truth vs. lie) x 2 (Enactment: enacted vs. intended crime) MANOVA's were performed on the behavioral data, whereas the MANOVA's on the ERP data contained the extra factor Electrode if necessary. The standardized mean difference $d$ was calculated as a measure of effect size, and Cohen's $f$ was calculated as effect size for interactions ${ }^{1}$. As a rule of thumb, 0.20, 0.50 and 0.80 were proposed as thresholds for "small", "moderate" and "large" effects of $d$, and 0.10, 0.25, and 0.40 as thresholds for "small", "moderate" and "large" effects of $f$ (Cohen, 1988, 1992). Because we used a repeated measures design, we corrected $d$ for intercorrelations (Cohen's $d$ for paired data; e.g., Morris \& DeShon, 2002) ${ }^{2}$.

\section{Results}

\section{1. Behavioral data}

Error rates, reaction times (RT), and RT standard deviations were analyzed with a 2 (Deception: truth vs. lie) x 2 (Enactment: enacted vs. intended crime) repeated measures MANOVA. ${ }^{3}$ The 2 x 2 MANOVA on error percentage revealed a significant main effect of Deception, $F(1,19)=30.97, p<.001, d=1.24,95 \%$ CI $[0.66,1.83]$, with a higher error rate $(\%)$ in the lie condition $(M=16.94, S D=12.31)$ compared to the truth condition $(M=8.93$, $S D=6.66)$. The Enactment effect and the interaction effect were not significant, $F$ 's $<1$. The 2 x 2 MANOVA on reaction times indicated a significant main effect of Deception $F(1,19)$ $=73.36, p<.001, d=1.91,95 \%$ CI $[1.18,2.65]$, with longer RTs (in milliseconds) in the lie condition $(M=784, S D=104)$ compared to the truth condition $(M=680, S D=85)$. The

\footnotetext{
${ }^{1}$ We calculated the effect size $f$ using the following formula: $f=\sqrt{ }\left[\eta_{\mathrm{p}}{ }^{2} /\left(1-\eta_{\mathrm{p}}{ }^{2}\right)\right]$

${ }^{2}$ We calculated the effect size $d$ using the following formula: $d=M_{1}-M_{2} /\left(\sqrt{S} S D_{1}^{2}+S D_{2}{ }^{2}-2 * r_{12} * S D_{1} * S D_{2}\right)$

${ }^{2}$ We calculated the effect size $d$ using the following formula: $d=M_{1}-M_{2} /\left(\sqrt{ } S D_{1}{ }^{2}+S D_{2}{ }^{2}-2 * r_{12} * S D_{1} * S D_{2}\right)$

${ }^{3}$ Both question types (enacted/planned crime versus control crime) were taken into the analyses. Because there was no significant interaction of Question type with Deception or Enactment in our analyses, the factor Question type was dropped.
} 
Enactment effect and the interaction effect were not significant, $F$ 's $<2.36$. The 2 x 2 MANOVA on the RT standard deviations revealed a significant main effect of Deception, $F(1,19)=5.13, p<.05, d=0.51,95 \%$ CI [0.04, 0.97], with a higher mean RT standard deviation in the lie condition $(M=259, S D=46)$ compared to the truth condition $(M=247$, $S D=44)$. The Enactment effect and the interaction effect were not significant, $F$ 's $<1$.

\subsection{ERP data}

\subsubsection{CNV}

Visual inspection of the grand average waveforms revealed a CNV at all three electrodes, starting around $1000 \mathrm{~ms}$ after the presentation of the cue (Figure 2). Furthermore, visual inspection suggested a difference between truth telling and lying in $\mathrm{CNV}$ at the frontal electrodes.

\section{- INSERT FIGURE 2 ABOUT HERE -}

The mean activity for the CNV in the interval between 1000 and $1500 \mathrm{~ms}$ was analyzed with a 2 (Deception: truth vs. lie) x 2 (Enactment: enacted vs. intended crime) x 3 (Electrode: $\mathrm{Fz}$ vs. $\mathrm{FCz}$ vs. $\mathrm{Cz}$ ) MANOVA. There were no significant main effects of Deception, $F(1,19)=1.71, p=.206, d=0.29,95 \%$ CI $[-0.16,0.74]$, or Enactment, $F(1,19)=$ $0.00, p=.953, d=0.01,95 \%$ CI [-0.43, 0.45]. The significant main effect of Electrode, $F(2$, 18) $=4.39, p<.05$ was subsumed under the significant interaction effect of Deception $\mathrm{x}$ Electrode, $F(2,18)=3.69, p<.05, f=0.64$. All other effects were not significant, all $F^{\prime}$ 's $<$ 1.90. Paired sample t-tests on the difference between the truth and the lie condition at every electrode revealed a marginally significant effect for a more negative CNV for the lie condition compared to the truth condition at Fz, $t(19)=1.98, p=.062, d=0.44,95 \%$ CI [$0.02,0.90]$, and no significant effects at the other two electrodes, $t$ 's $<1.36$.

\subsubsection{Stimulus-locked LRP}

The grand average waveforms of the stimulus-locked LRP revealed a clear LRP in both truth conditions starting around $250 \mathrm{~ms}$ after the keyword. Compared to the LRPs in the truth conditions, the LRPs in the lie conditions appeared flatter and slower rising (Figure 3). We did not observe an initial activation towards the incorrect truth response in both lie conditions. 
As the visual inspection of the grand averages of the stimulus-locked LRPs suggested differences between truth and lie conditions between $300-600 \mathrm{~ms}$ and between $600-900 \mathrm{~ms}$, mean activity in both interval was analyzed with a 2 (Deception: truth vs. lie) x 2 (Enactment: enacted vs. intended crime) MANOVA. For the $300-600 \mathrm{~ms}$ interval, there were no significant main effects of Deception, $F(1,19)=0.02, p=.889, d=0.03$, 95\% CI [-0.41, 0.47], or Enactment, $F(1,19)=0.39, p=.542, d=0.14,95 \%$ CI [-0.30, 0.58]. There was also no significant interaction effect, $F(1,19)=0.70, p=.413, f=0.19$. For the $600-900 \mathrm{~ms}$ interval, there were no significant main effects of Deception, $F(1,19)=2.20, p=.154, d=$ $0.33,95 \%$ CI $[-0.19,0.78]$, or Enactment, $F(1,19)=0.05, p=.826, d=0.05,95 \%$ CI $[-0.39$, 0.49]. There was also no significant interaction effect, $F(1,19)=0.73, p=.402, f=0.20{ }^{4}$

To explore further possible deception effects, exploratory analyses were run on the response-locked LRPs as well as on the onsets of stimulus- and response-locked LRPs. As we did not have any a-priori hypotheses and the analyses did not yield clear results, they are reported in the appendix.

\subsubsection{CRN}

Visual inspection of the grand average waveforms of the CRN revealed a negative peak around $50 \mathrm{~ms}$ after correct responses (Figure 4).

\section{- INSERT FIGURE 4 ABOUT HERE -}

The mean activity for the CRN in the interval between 0 and $100 \mathrm{~ms}$ was analyzed with a 2 (Deception: Truth vs. Lie) x 2 (Enactment: enacted vs. intended crime) x 4 (Electrode: $\mathrm{Fz}$ vs. $\mathrm{FCz}$ vs. $\mathrm{Cz}$ vs. $\mathrm{Pz}$ ) MANOVA. There was no significant main effect of Enactment, $F(1,19)=0.26, p=.615, d=0.11,95 \%$ CI $[-0.33,0.55]$. The main effects of Electrode, $F(3,17)=25.15, p<.001$, and Deception, $F(1,19)=5.33, p<.05, d=0.52,95 \%$ CI $[0.05,0.98]$, were subsumed under the Deception $x$ Electrode interaction effect, $F(3,17)=$ $3.81, p<.05, f=0.82$. There were no other significant interaction effects, all $F$ ' $s<1$. Paired sample t-tests on the difference between the truth and the lie condition at every electrode revealed a more negative $\mathrm{CRN}$ for the truth condition compared to the lie condition at $\mathrm{Fz}$, $t(19)=3.09, p<.01, d=0.69,95 \%$ CI $[0.20,1.18]$, and FCz $t(19)=2.30, p<.05, d=0.53$, $95 \% \mathrm{CI}[0.06,1.00]$, and a tendency towards a significant effect in the same direction at $\mathrm{Cz}$,

\footnotetext{
${ }^{4}$ Note that we also explored LRP results at FC3/FC4. Including the LRP at these electrodes in our analyses did not change the pattern of results.
} 
$t(19)=1.76, p=.094, d=0.39,95 \%$ CI $[-0.06,0.85]$. The difference in the same direction at Pz was not significant, $t(19)=1.39, \mathrm{p}=.182, d=0.31,95 \%$ CI $[-0.09,0.71]$.

\subsubsection{N200 and P300}

Visual inspection of the grand average waveforms revealed a $\mathbf{N 2 0 0}$ around $300 \mathrm{~ms}$ after the keyword at fronto-central electrodes and a P300 around $400 \mathrm{~ms}$ after the keyword at the parietal electrode (Figure 5).

\section{- INSERT FIGURE 5 ABOUT HERE -}

The mean activity for the N200 in the interval between 250 and 350 was analyzed with a 2 (Deception: Truth vs. Lie) x 2 (Enactment: enacted vs. intended crime) x 3 (Electrode: Fz vs. $\mathrm{FCz}$ vs. $\mathrm{Cz}$ ) MANOVA. There was no significant main effect of Enactment, $F(1,19)=$ $0.09, p=.774, d=0.06,95 \%$ CI $[-0.37,0.50]$. There was a significant effect of Electrode, $F(2,18)=12.90, p<.001$, and a marginally significant effect of Deception, $F(1,19)=4.30, p$ $=.052, d=0.46,95 \%$ CI $[0.00,0.93]$, with a more negative N200 for the lie condition compared to the truth condition. There was a marginally significant interaction of Deception $\mathrm{x}$ Electrode, $F(2,18)=2.99, p=.076, f=0.58$. All other interaction effects were not significant, all $F$ 's $<1.03$. Paired sample t-tests on the difference between the truth and the lie condition at every electrode revealed a more negative N200 for the lie condition compared to the truth condition at FCz, $t(19)=2.23, p<.05, d=0.50,95 \%$ CI $[0.03,0.96]$, and marginally significant differences in the same direction at Fz, $t(19)=1.79, p=.089, d=0.40,95 \%$ CI [$0.06,0.85]$, and $\mathrm{Cz}, t(19)=2.07, p=.052, d=0.46,95 \% \mathrm{CI}[0.00,0.92]$.

The mean activity for the P300 in the interval between 350 and 800 was analyzed with a 2 (Deception: Truth vs. Lie) x 2 (Enactment: enacted vs. intended crime) x 5 (Electrode: Fz vs. $\mathrm{FCz}$ vs. $\mathrm{Cz}$ vs. Pz vs. Oz) MANOVA. There was no significant main effect of Enactment, $F(1,19)=0.07, p=.797, d=0.06,95 \%$ CI $[-0.38,0.50]$. The main effects of Electrode, $F(3$, $17)=36.01, p<.001$, and Deception, $F(1,19)=4.28, p=.052, d=0.46,95 \%$ CI $[0.00,0.92]$, were subsumed under the significant Deception $\mathrm{x}$ Electrode interaction, $F(4,16)=7.23, p<$ $.01, f=1.34$. There were no other significant interaction effects, all $F$ 's $<1$. Paired sample ttests on the difference between the truth and the lie condition at every electrode revealed a smaller (i.e., less positive) P300 for the lie condition compared to the truth condition at $\mathrm{FCz}$, $t(19)=2.24, p<.05, d=0.50,95 \%$ CI $[0.04,0.97], \mathrm{Cz}, t(19)=3.03, p<.01, d=0.68,95 \%$ 
CI $[0.19,1.26]$, and Pz, $t(19)=2.28, p<.05, d=0.51,95 \%$ CI $[0.04,0.98]$. Differences at Fz and $\mathrm{Oz}$ were not significant, $t$ 's $<1.17$.

\section{Discussion}

Lying comes at a cognitive cost, as indexed by prolonged RTs for lying compared to truth telling. The current study aimed to validate this finding with ERPs and to elucidate the cognitive processes underlying this cost. In the current study, we used a mock crime procedure with both an executed as well as a merely planned crime, and extended the Sheffield Lie Test to measure different event-related components: the CNV, the LRP, the CRN, the N200, and the P300.

In line with our hypothesis and earlier research (Dong \& Wu, 2010; Fang et al., 2003; Sun et al., 2011), the analysis of the CNV revealed a marginally significant effect with a more negative $\mathrm{CNV}$ for lying compared to truth telling. However, in contrast to earlier studies, the effect was restricted to $\mathrm{Fz}$ and only of small to medium size $(d=0.44,95 \%$ CI $[-0.02,0.90])$. We calculated Cohen's $d$ for those earlier studies by using the $F$-values reported for the lietruth contrasts in the intervals and over the electrodes that showed an effect in the particular studies. This indicated very large effects in those earlier studies $(d=1.18-23.77)$. One fundamental difference between those studies and our study may explain the observed difference in effect sizes: while previous studies measured the CNV after the presentation of the crucial stimulus, we measured the CNV after the truth or lie cue, but before participants could determine the correct response. Therefore, whereas in earlier research the anticipation of truth telling and lying cannot be distinguished from stimulus processing and preparation of the already known correct response, CNV effects in our design only reflect the pure anticipation and preparation of truth telling and lying. Our results suggest that although deception effects on the CNV seem to be smaller after the removal of this confounding factor, the anticipation of deception still may lead to an enlarged CNV compared to the anticipation of truth telling. Note, however, that the effect was only marginally significant and that the large confidence intervals indicate that more research is needed to obtain more precise estimates. Also, a within-study comparison of both design types is needed to determine whether those differences can indeed explain the observed differences in effect sizes.

The $\mathrm{CNV}$, and more specifically the late $\mathrm{CNV}$, has been proposed to indicate various aspects of increased anticipatory cognitive load, as for instance increased working memory activity, increased motivation, and stronger outcome monitoring (e.g., Brunia \& van Boxtel, 
2001; Brunia et al., 2012; Honda et al., 1996; McCallum \& Curry, 1993; Wascher et al., 1996). These interpretations of the CNV fit well with the cognitive processes proposed to underlie successful deception. Interestingly, using a source analysis technique, Sun et al. (2011) identified the right inferior frontal gyrus, a brain region that has been proposed to be crucially involved in response inhibition processes (Aron et al., 2004), as possible generator of the enhanced late CNV in their study. This provides a further indication that inhibition of the prepotent truthful response might be crucially involved in the enlarged cognitive load in deception.

Interesting in this context is our result that the P300 was significantly reduced during lying compared to truth telling (Hu et al., 2011; Johnson et al., 2003, 2005; Pfister et al., 2014; Wu et al., 2009). The P300 component has been shown to be influenced by cognitive load, and reduced P300 amplitudes have been observed in paradigms that required the division of attention between different tasks (Isreal et al., 1980a,b; Kramer et al., 1985; Wickens et al., 1983). The reduced P300 for lying compared to truth telling in paradigms with equal proportions has consequently been interpreted as reflecting the dual task character of lying: lying requires the truth to be kept active, monitored and at the same time inhibited (see also Crist et al., 2009; Vrij et al., 2011). In our data, the reduced P300 together with the enhanced CNV for lying compared to truth telling support the cognitive load hypothesis in lying. Note that whereas our and other previous studies revealed a reduced P300 for lying compared to truth telling in paradigms using equal proportions of truth telling and lying, ERP studies using the Concealed Information Test (CIT) usually observe an opposite result pattern (e.g., Verschuere et al., 2009). In those studies, participants typically respond truthfully on the majority of trials, whereas they deceive only on a small number of trials (usually around $10 \%$ ). This oddball effect strongly increases P300 amplitudes and seems to override cognitive load effects of deception in the CIT.

The current study also employed three additional ERP components that have been proposed to index response conflict and response monitoring: the LRP, the N200, and the CRN. Based on the idea that the truth is initially activated and conflicts with the lie, we expected an initial LRP deflection towards the (incorrect) truth response in lie trials, and no deflection in truth trials (as e.g., in Flanker and Simon tasks; De Jong et al., 1994; Gratton et al., 1988; Sturmer et al., 2002). Neither the stimulus- nor the response locked LRPs showed such a deflection in lie trials (for the latter see appendix). Although visual inspection of the stimulus-locked grand average LRP waveforms revealed a flatter and slower rising waveform 
in the lie compared to the truth condition, the differences were not statistically significant. Also the earlier onset of the stimulus-locked LRP in the truth compared to the lie condition of $17 \mathrm{~ms}$ was not significant (see appendix). As such we found no evidence for an initial activation of the truthful response before lying.

We did, however, find a significant deception effect on the N200 at FCz, with a more pronounced N200 for lying compared to truth telling. This finding replicates findings of Hu et al. (2011). One possibility why deception may increase the N200 but not affect the LRP may be that lying initially induces conflict, yet that this conflict does not translate to actual response activation of the truthful response: response activation may only start after the correct deceptive response has been determined (see also Gamer et al., 2012; Suchotzki et al., in press; Verschuere et al., 2012). A closer look at the time course of the N200 and the stimulus-locked LRP in our study may support this explanation. Whereas the N200 occurred between 200 and $350 \mathrm{~ms}$, analyses on the onset latencies of the stimulus-locked LRP indicate that the LRP only started around $360 \mathrm{~ms}$ (see appendix).

Yet, given that other studies did also find evidence for an initial activation of the truth response, it may be too soon to dismiss this hypothesis. For instance, Duran et al. (2010) instructed participants to answer questions both truthfully and deceitfully by moving a Nintendo Wii Remote to "yes" or "no" - answers displayed on top of a screen. Tracking participants' arm movements, the authors observed a stronger deviation towards the notchosen (truthful) response during deceitful responding. Similarly, in three experiments, Hadar et al. (2012) found larger motor-evoked potentials for truthful compared to deceptive responses during the preparation of deceptive responses, and no such response competition during the preparation of truthful responses. Both studies strongly indicate an initial motor activation for the truthful response during lying. Certain features of our study may explain the absence of the initial truth activation when lying: (1) We presented the lie/truth cue $1500 \mathrm{~ms}$ before the actual response, which may have enabled participants to prepare their lie responses and suppress the truth response more effectively. (2) Our mock crime questions were quite complex compared to stimuli used by Duran et al. (2010) and Hadar et al. (2012). We tried to decrease complexity and promote fast responding by presenting the beginning of the question and the truth/lie cues before the actual response was required, so that only the last word had to be processed before the response could be given. Yet, together with the control questions for the past and the intended crimes, the questions referred to four different crime scenarios. This complexity might have prevented any automatic response activation. In lie trials, participants 
may strategically have waited with their response until they had determined the correct response. (3) The variance of RTs was greater in the lie condition compared to the truth condition (see also Johnson et al., 2004, 2005), which may have resulted in a more "jittered" stimulus-locked LRP in the lie condition and may also have "washed out" any incorrect lateralization after averaging both within and across participants. Therefore, under consideration of the points raised above, future studies might adapt the Sheffield Lie Test to increase sensitivity to initial truth activation, by using simpler questions, delivering the lie/truth cue at the same time as the crucial stimulus, and reinforcing truth telling, for instance by increasing the percentage of questions that have to be answered truthfully to $60 \%$ or $80 \%$ (Verschuere et al., 2011).

Regarding the CRN, we predicted a stronger CRN after lying than after truth telling. Yet, unexpectedly, we found a reversed effect (i.e., a smaller CRN after lying compared to truth telling). This result is inconsistent with previous results (Johnson et al., 2004, 2005; Johnson et al., 2008). However, although Kireev et al. (2008) and Dong et al. (2010) replicated the finding of a larger CRN for lying compared to truth telling, they also found that this deception CRN effect was influenced by task characteristics, and that it was reversed when participants were under the influence of alcohol. This provides a first indication that the CRN deception effect is malleable and sensitive to task characteristics. A possible explanation can be found in how we motivated participants to deceive (see also Verschuere \& Shalvi, 2014). Participants were promised an extra reward for not revealing their guilt. Importantly, by promoting and rewarding successful lying, lie responses may have been perceived as the actual "correct" responses, whereas the truthful responses may have been perceived as the "incorrect" responses in the sense of being inconsistent with the goal of deceiving and earning the extra reward. Related to this explanation is a second possibility. Aside from error and conflict monitoring, the ERN has also been suggested to be sensitive to the emotional valence of errors (Aarts et al., 2013; Luu et al., 2000). Within this line of reasoning, smaller CRNs would correspond to a more positive evaluation of an action. Within our experiment, the reversed difference between the truth telling and lying CRN might therefore not only reflect less conflict during lying (as lying is the desired outcome), but also a more positive spontaneous evaluation of successful lying and a more negative spontaneous evaluation of successful (undesired) truth telling. In sum, the smaller CRN for lying than for truth telling may be explained by participants' large motivation to deceive, which may have turned deceitful responses in the actual correct responses, or by the more positive evaluation of lie 
responses due to the desired financial reward. These interpretations could be empirically tested by manipulating participants' motivation to deceive and/or by measuring affect/valence connected with truthful or deceitful responding (e.g., by implementing an affective priming task within the Sheffield Lie Test similar to Aarts et al., 2013).

It would also be interesting for future research to follow up on the dissociation between N200 and CRN observed in the current study. The N200 and the CRN-related ERN have been hypothesized to be generated in the same neural source, the anterior cingulated cortex (ACC), and to be explained within the same theoretical framework (i.e., conflictmonitoring theory; Folstein \& Van Petten, 2008; Van Veen \& Carter, 2002). However, there are other studies that observed dissociations between the N200 and the ERN (Ridderinkhof et al., 2002; Swick \& Turken, 2002), and it has been debated whether those dissociations can be accounted for by conflict-monitoring theory (Yeung \& Cohen, 2006). It would be very interesting for future research to investigate how certain designs characteristics (e.g., motivating participants) may differentially influence the N200 and the CRN during lying.

Our results have practical implications. Based on earlier results, the CNV was proposed as a 'new indicator for lie detection' (Fang et al., 2003). Yet, our results strongly indicate that effect sizes and even the direction of ERP deception effects seem to vary as a function of design and task characteristics and that such applied claims are premature. They should be treated with caution, before future research can clarify moderating factors of such deception ERP effects.

Our study has several limitations. In the Sheffield lie Test, participants are typically cued to either lie or tell the truth on different trials. This increases experimental control, yet restricts the interpretation of our data in two aspects. First, we cannot exclude that participants sometimes made deliberate 'errors'. They may, for instance, sometimes lie instead of respond truthfully, in order to hide what they did and increase chances of obtaining the financial reward. The observed low error rate suggests that participants do not apply this strategy often. Also, by only taking correct responses in the RT and ERP analyses, we exclude trials on which this may have occurred. It would, however, be very interesting for future research to investigate whether participants in the Sheffield Lie Test indeed employ such a strategy, for instance by asking participants after error trials whether the errors were deliberate or intentional. 
Second, there may be differences between instructed and self-chosen lying. Evidence so far is mixed. For instance, whereas the majority of research found larger CNVs for lying compared to truth telling (Dong \& Wu, 2010; Fang et al., 2003; Sun et al., 2011), Panasiti et al. (2014) found the opposite effect in a design in which participants freely choose whether to lie or tell the truth to maximize financial gain. In this study, the Bereitschaftspotential (BP), which is an ERP component similar to the CNV, was larger for truth telling compared to lying. Also, in contrast to results of our study and the study of Hu et al., (2011), Pfister et al. (2014) recently found a larger N200 for truth telling compared to lying in a study in which participants freely choose whether to truthfully indicate the location of a knife in order to help a police officer. And as a final example, the larger P300 for truth telling compared to lying has consistently been found in studies using instructed lies (Johnson et al., 2003, 2005; Hu et al., 2011; Wu et al., 2009), yet not in all studies using freely chosen lies (e.g., Panasiti et al., 2014; Pfister et al., 2014; Wu et al., 2009). Design differences aside from instructed vs. selfchosen deception hinder comparisons between studies, and more research directly comparing both types of deception is needed (e.g., Wu et al., 2009).

To sum up, our results support the cognitive view on deception by indicating that lying comes at a higher cognitive cost, as suggested by the deception effects on the behavioral data, the $\mathrm{CNV}$, and the P300. Evidence for the role of response conflict was mixed. Note that these effects were found for lying about past behavior (i.e., an executed mock crime), but also for future intended behavior (i.e., a planned mock crime), contributing to an emerging research line on lying about merely planned acts. Our findings also stipulate that more research is needed to clarify the specific cognitive processes that underlie the cognitive cost of lying and that those cognitive processes may, for instance, be moderated by participants' motivation to deceive. 
CNV, LRP, AND CRN EFFECTS IN DECEPTION

\section{Acknowledgments}

This research was supported by an ECRP Grant (09-ECRP-025; FWO Grant ESF 3G099310). We thank Valentina Rossi for her comments on our CNV analysis and Tom Everaert for his help with the jackknife analyses. 


\section{References}

Aarts, K., De Houwer, J., \& Pourtois, G., 2013. Erroneous and Correct Actions Have a Different Affective Valence: Evidence From ERPs. Emotion 13(5), 960-973. doi:10.1037/A0032808

Aron, A.R., Robbins, T.W., \& Poldrack, R.A., 2004. Inhibition and the right inferior frontal cortex. Trends Cogn. Sci. 8(4), 170-177. doi:10.1016/j.tics.2004.02.010

Botvinick, M.M., Braver, T.S., Barch, D.M., Carter, C.S., \& Cohen, J.D., 2001. Conflict monitoring and cognitive control. Psychol. Rev. 108(3), 624-652. doi:10.1037/0033295X.108.3.624

Brunia, C.H., \& van Boxtel, G.J., 2001. Wait and see. Int. J. Psychophysiol. 43(1), 59-75. doi:10.1016/S0167-8760(01)00179-9

Brunia, C.H.M., van Boxtel, G.J.M., \& Böcker, K.B.E., 2012. Negative slow waves as indices of anticipation: The Bereitschaftspotential, the Contingent Negative Variation, and the Stimulus-Preceding Negativity. In: Luck, S.J., Kappenman, E.S. (Eds.), Oxford Handbook of Event-Related Potential Components, Oxford University Press, New York, pp. 189-207. doi:10.1093/oxfordhb/9780195374148.013.0108

Christ, S.E., Van Essen, D.C., Watson, J.M., Brubaker, L.E., \& McDermott, K.B., 2009. The contributions of prefrontal cortex and executive control to deception: evidence from activation likelihood estimate meta-analyses. Cereb. Cortex 19(7), 1557-1566. doi:10.1093/cercor/bhn189

Clemens, F., Granhag, P.A., \& Strömwall, L.A., 2011. Eliciting Cues to False Intent. Law Hum. Behav. 35(6), 512-522. doi:10.1007/s10979-010-9258-9

Cohen, J., 1988. Statistical power analysis for the behavioural sciences. Lawrence Erlbaum, Hillsdale.

Cohen, J., 1992. A Power Primer. Psychol. Bull. 112(1), 155-159. doi:10.1037/00332909.112.1.155

Coles, M.G., 1989. Modern mind-brain reading: psychophysiology, physiology, and cognition. Psychophysiology 26(3), 251-269. doi:10.1111/j.1469-8986.1989.tb01916.x

Coles, M.G., Scheffers, M.K., \& Holroyd, C.B., 2001. Why is there an ERN/Ne on correct trials? Response representations, stimulus-related components, and the theory of errorprocessing. Biol. Psychol. 56(3), 173-189. doi:10.1016/S0301-0511(01)00076-X

De Jong, R., Liang, C.C., \& Lauber, E., 1994. Conditional and Unconditional Automaticity - a Dual-Process Model of Effects of Spatial Stimulus - Response Correspondence. J. 
Exp. Psychol. Hum. Percept. Perform. 20(4), 731-750. doi:10.1037/00961523.20.4.731

Debey, E., Verschuere, B., \& Crombez, G., 2012. Lying and executive control: an experimental investigation using ego depletion and goal neglect. Acta Psychol. 140(2), 133-141. doi:10.1016/j.actpsy.2012.03.004

DePaulo, B.M., Lindsay, J.J., Malone, B.E., Muhlenbruck, L., Charlton, K., \& Cooper, H., 2003. Cues to deception. Psychol. Bull. 129(1), 74-118. doi:10.1037//00332909.129.1.74

Dong, G., Hu, Y., \& Wu, H., 2010. The presentation order of cue and target matters in deception study. Behav. Brain Funct. 6, 63. doi:10.1186/1744-9081-6-63

Dong, G., \& Wu, H., 2010. Attempting to hide our real thoughts: electrophysiological evidence from truthful and deceptive responses during evaluation. Neurosci. Lett. 479(1), 1-5. doi:10.1016/j.neulet.2010.05.014

Duran, N.D., Dale, R., \& McNamara, D.S., 2010. The action dynamics of overcoming the truth. Psychon. Bull. Rev. 17(4), 486-491. doi:10.3758/Pbr.17.4.486

Falkenstein, M., Hohnsbein, J., Hoormann, J., \& Blanke, L., 1991. Effects of crossmodal divided attention on late ERP components. II. Error processing in choice reaction tasks. Electroencephalogr. Clin. Neurophysiol. 78(6), 447-455. doi:10.1016/00134694(91)90062-9

Fang, F., Liu, Y., \& Shen, Z., 2003. Lie detection with contingent negative variation. Int. J. Psychophysiol. 50(3), 247-255. doi:10.1016/S0167-8760(03)00170-3

Farrow, T.F., Hopwood, M.C., Parks, R.W., Hunter, M.D., \& Spence, S.A., 2010. Evidence of mnemonic ability selectively affecting truthful and deceptive response dynamics. Am. J. Psychol. 123(4), 447-453. doi:10.5406/amerjpsyc.124.4.0447

Folstein, J.R., \& Van Petten, C., 2008. Influence of cognitive control and mismatch on the N2 component of the ERP: a review. Psychophysiology 45(1), 152-170. doi:10.1111/j.1469-8986.2007.00602.x

Fullam, R.S., McKie, S., \& Dolan, M.C., 2009. Psychopathic traits and deception: functional magnetic resonance imaging study. Br. J. Psychiatry 194(3), 229-235. doi:10.1192/bjp.bp.108.053199

Furedy, J.J., Davis, C., \& Gurevich, M., 1988. Differentiation of deception as a psychological process: a psychophysiological approach. Psychophysiology 25(6), 683-688. doi:10.1111/j.1469-8986.1988.tb01908.x 
Gamer, M., Klimecki, O., Bauermann, T., Stoeter, P., \& Vossel, G., 2012. fMRI-activation patterns in the detection of concealed information rely on memory-related effects. Soc. Cogn. Affect. Neurosci. 7(5), 506-515. doi:10.1093/Scan/Nsp005

Gehring, W.J., Goss, B., Coles, M.G.H., Meyer, D.E., \& Donchin, E., 1993. A Neural System for Error-Detection and Compensation. Psychol. Sci. 4(6), 385-390. doi:10.1111/j.1467-9280.1993.tb00586.x

Granhag, P.A., \& Knieps, M., 2011. Episodic future thought: Illuminating the trademarks of forming true and false intentions. Appl. Cogn. Psychol. 25(2), 274-280. doi:10.1002/acp.1674

Gratton, G., Coles, M.G., \& Donchin, E., 1983. A new method for off-line removal of ocular artifact. Electroencephalogr. Clin. Neurophysiol. 55(4), 468-484. doi:10.1016/00134694(83)90135-9

Gratton, G., Coles, M.G., Sirevaag, E.J., Eriksen, C.W., \& Donchin, E., 1988. Pre- and poststimulus activation of response channels: a psychophysiological analysis. J. Exp. Psychol. Hum. Percept. Perform. 14(3), 331-344. doi:10.1037//0096-1523.14.3.331

Hadar, A.A., Makris, S., \& Yarrow, K., 2012. The truth-telling motor cortex: Response competition in M1 discloses deceptive behaviour. Biol. Psychol. 89(2), 495-502. doi:10.1016/j.biopsycho.2011.12.019

Honda, M., Barrett, G., Yoshimura, N., Ikeda, A., Nagamine, T., \& Shibasaki, H., 1996. Event-related potentials during paired associate memory paradigm. Electroencephalogr. Clin. Neurophysiol. 100(5), 407-421. doi:10.1016/S0921884X(96)95083-3

Hu, X., Chen, H., \& Fu, G., 2012. A repeated lie becomes a truth? The effect of intentional control and training on deception. Front. Psychol. 3, 488. doi:10.3389/fpsyg.2012.00488

Hu, X., Wu, H., \& Fu, G., 2011. Temporal course of executive control when lying about selfand other-referential information: an ERP study. Brain Res. 1369, 149-157. doi:10.1016/j.brainres.2010.10.106

Isreal, J.B., Chesney, G.L., Wickens, C.D., \& Donchin, E., 1980a. P300 and Tracking Difficulty: Evidence For Multiple Resources in Dual-Task Performance. Psychophysiology, 17(3), 259-273. doi: 10.1111/j.1469-8986.1980.tb00146.x

Isreal, J.B., Wickens, C.D., Chesney, G.L., \& Donchin, E., 1980b. The event-related brain potential as an index of display-monitoring workload. Proc. Hum. Fact. Ergon. Soc. Annu. Meet. 22(2), 211-224. doi:10.1177/001872088002200210 
Jasper, H.H., 1958. The ten-twenty electrode system of the International Federation. Electroencephalogr. Clin. Neurophysiol. 10, 367-380.

Johnson Jr, R., Barnhardt, J., \& Zhu, J., 2003. The deceptive response: effects of response conflict and strategic monitoring on the late positive component and episodic memoryrelated brain activity. Biol. Psychol. 64(3), 217-253. doi:10.1016/j.biopsycho.2003.07.006

Johnson, R., Jr., Barnhardt, J., \& Zhu, J., 2004. The contribution of executive processes to $\begin{array}{llll}\text { deceptive } & \text { responding. } & \text { Neuropsychologia }\end{array}$ doi:10.1016/j.neuropsychologia.2003.12.005

Johnson, R., Jr., Barnhardt, J., \& Zhu, J., 2005. Differential effects of practice on the executive processes used for truthful and deceptive responses: an event-related brain potential study. Cogn. Brain Res. 24(3), 386-404. doi:10.1016/j.cogbrainres.2005.02.011

Johnson, R., Jr., Henkell, H., Simon, E., \& Zhu, J., 2008. The self in conflict: the role of executive processes during truthful and deceptive responses about attitudes. Neuroimage 39(1), 469-482. doi:10.1016/j.neuroimage.2007.08.032

Kireev, M.V., Pakhomov, S.V., \& Medvedev, S.V., 2008. Cerebral mechanisms of error detection during deceptive responses in the normal state and under the influence of alcohol. Hum. Physiol. 34, 141-149. doi:10.1134/S0362119708020023

Kramer, A.F., Wickens, C.D., \& Donchin, E., 1985. Processing of stimulus properties: Evidence for dual-task integrality. J. Exp. Psychol. Hum. Percept. Perform. 11(4), 393. doi:10.1037//0096-1523.11.4.393

Luu, P., Collins, P., \& Tucker, D.M., 2000. Mood, personality, and self-monitoring: negative affect and emotionality in relation to frontal lobe mechanisms of error monitoring. $\mathrm{J}$. Exp. Psychol. Gen. 129(1), 43-60. doi:10.1037/0096-3445.129.1.43

Lykken, D.T., 1998. A tremor in the blood: Uses and abuses of the lie detector. Plenum Press, New York.

McCallum, W.C., \& Curry, S.H., 1993. Slow potential changes in the human brain. Plenum Press, New York. doi:10.1007/978-1-4899-1597-9

Meijer, E.H, Verschuere, B., \& Merckelbach, H., 2010. Detecting criminal intent with the concealed information test. Open Criminol. J. 3, 44-47. doi:10.2174/1874917801003010044 
Meixner, J.B, \& Rosenfeld, J.P., 2011. A mock terrorism application of the P300-based concealed information test. Psychophysiology 48(2), 149-154. doi:10.1111/j.14698986.2010.01050.x

Miller, J., Patterson, T., \& Ulrich, R., 1998. Jackknife-based method for measuring LRP onset latency differences. Psychophysiology 35(1), 99-115. doi:10.1111/1469-8986.3510099

Morris, S.B., \& DeShon, R.P., 2002. Combining effect size estimates in meta-analysis with repeated measures and independent-groups designs. Psychol. Methods 7(1), 105-125. doi:10.1037/1082-989X.7.1.105

National Research Council, 2003. The polygraph and lie detection. Committee to review the scientific evidence on the Polygraph. Division of Behavioral and Social Sciences and Education, The National Academic Press, Washington, DC.

Noordraven, E., \& Verschuere, B., 2013. Predicting the Sensitivity of the Reaction Timebased Concealed Information Test. Appl. Cogn. Psychol 27(3), 328-335. doi:10.1002/acp.2910

Panasiti, M.S., Pavone, E.F., Mancini, A., Merla, A., Grisoni, L., \& Aglioti, S.M., 2014. The motor cost of telling lies: Electrocortical signatures and personality foundations of spontaneous deception. Soc. Neurosci. 9(6), 573-589. doi:10.1080/17470919.2014.934394

Pfister, R., Foerster, A., \& Kunde, W., 2014. Pants on fire: The electrophysiological signature of telling a lie. Soc. Neurosci. 9(6), 562-572. doi:10.1080/17470919.2014.934392

Polich, J., 2012. Neuropsychology of P300. Luck, S.J., \& Kappenman, E.S. (Eds.), The Oxford handbook of event-related potential components, Oxford University Press., 159-188. doi:10.1093/oxfordhb/9780195374148.013.0089

Reid, R.E., 1947. A revised questioning technique in lie-detection tests. J. Crim. Law Criminol. 37(6), 542-547. doi:10.2307/1138979

Ridderinkhof, K.R., de Vlugt, Y., Bramlage, A., Spaan, M., Elton, M., Snel, J., \& Band, G.P.H. (2002). Alcohol consumption impairs detection of performance errors in mediofrontal cortex. Science, 298, 2209-2211. doi:10.1126/science.1076929

Seymour, T.L., \& Schumacher, E.H., 2009. Electromyographic evidence for response conflict in the exclude recognition task. Cogn. Affect. Behav. Neurosci. 9(1), 71-82. doi:10.3758/CABN.9.1.71

Simmons, J.P., Nelson, L.D., \& Simonsohn, U., 2011. False-positive psychology undisclosed flexibility in data collection and analysis allows presenting anything as significant. Psychol. Sci. 22(11), 1359-1366. doi:10.1177/0956797611417632 
Smulders, F.T., 2010. Simplifying jackknifing of ERPs and getting more out of it: retrieving estimates of participants' latencies. Psychophysiology 47(2), 387-392. doi:10.1111/j.1469-8986.2009.00934.x

Smulders, F.T.Y., \& Miller, J.O., 2012. The Lateralized Readiness Potential. In: Luck, S.J., Kappenman, E.S. (Eds.), Oxford Handbook of Event-Related Potential Components, Oxford University Press, New York, pp. 209-229. doi:10.1093/oxfordhb/9780195374148.013.0115

Spence, S.A., Farrow, T.F., Herford, A.E., Wilkinson, I.D., Zheng, Y., \& Woodruff, P. W., 2001. Behavioural and functional anatomical correlates of deception in humans. Neuroreport 12(13), 2849-2853. doi:10.1097/00001756-200109170-00019

Stürmer, B., Leuthold, H., Soetens, E., Schroter, H., \& Sommer, W., 2002. Control over location-based response activation in the Simon task: behavioral and electrophysiological evidence. J. Exp. Psychol. Hum. Percept. Perform. 28(6), 13451363. doi:10.1037/0096-1523.28.6.1345

Suchotzki, K., Crombez, G., Debey, E., Van Oorsouw, K., \& Verschuere, B., in press. In Vino Veritas? - Alcohol, Response Inhibition and Lying. Alcohol Alcohol. doi:10.1093/alcalc/agu079

Sun, S.Y., Mai, X., Liu, C., Liu, J.Y., \& Luo, Y.J., 2011. The processes leading to deception: ERP spatiotemporal principal component analysis and source analysis. Soc. Neurosci. 6, 348-359. doi:10.1080/17470919.2010.544135

Sutton, S., Braren, M., Zubin, J., \& John, E.R., 1965. Evoked-potential correlates of stimulus uncertainty. Science, 150(3700), 1187-1188. doi: 10.1126/science.150.3700.1187

Swick, D., \& Turken, A.U., 2002. Dissociation between conflict detection and error monitoring in the human anterior cingulate cortex. Proc. Natl. Acad. Sci. USA, 99, 16354-16359. doi:10.1073/pnas.252521499

Ulrich, R., \& Miller, J., 2001. Using the jackknife-based scoring method for measuring LRP onset effects in factorial designs. Psychophysiology 38(5), 816-827. doi:10.1111/1469-8986.3850816

Van Bockstaele, B., Verschuere, B., Moens, T., Suchotzki, K., Debey, E., \& Spruyt, A., 2012. Learning to lie: effects of practice on the cognitive cost of lying. Front. Psychol. 3, 526-552. doi:10.3389/fpsyg.2012.00526

Van Veen, V., \& Carter, C.S., 2002. The timing of action-monitoring processes in the anterior cingulate cortex. J. Cogn. Neurosci. 14(4), 593-602. doi:10.1162/08989290260045837 
Verschuere, B., \& De Houwer, J., 2011. Detecting concealed information in less than a second: response latency-based measures. In: Verschuere, B., Ben-Shakhar, G, Meijer, E. (Eds.), Memory Detection: Theory and Application of the Concealed Information Test, Cambridge University Press, Cambridge, pp. 46-63. doi:10.1017/CBO9780511975196.004

Verschuere, B., Rosenfeld, J.P., Winograd, M.R., Labkovsky, E., \& Wiersema, R., 2009. The role of deception in P300 memory detection. Legal Criminol Psych, 14(2), 253-262. doi:10.1348/135532508X384184

Verschuere, B., Schuhmann, T., \& Sack, A.T., 2012. Does the inferior frontal sulcus play a functional role in deception? A neuronavigated theta-burst transcranial magnetic stimulation study. Front. Hum. Neurosci. 6, 284. doi:10.3389/fnhum.2012.00284

Verschuere, B., Shalvi, S., 2014. The Truth Comes Naturally! Does It? J. Lang. Soc. Psychol. Advance online publication. doi:10.1177/0261927X14535394

Verschuere, B., Spruyt, A., Meijer, E.H., \& Otgaar, H., 2011. The ease of lying. Conscious. Cogn. 20(3), 908-911. doi:10.1016/j.concog.2010.10.023

Vrij, A., Fisher, R., Mann, S., \& Leal, S., 2006. Detecting deception by manipulating cognitive load. Trends Cogn. Sci. 10(4), 141-142. doi:10.1016/j.tics.2006.02.003

Vrij, A., Granhag, P. A., Mann, S., \& Leal, S., 2011. Outsmarting the Liars: Toward a Cognitive Lie Detection Approach. Curr. Dir. Psychol. Sci. 20(1), 28-32. doi:10.1177/0963721410391245

Walczyk, J.J., Roper, K.S., Seemann, E., \& Humphrey, A.M., 2003. Cognitive mechanisms underlying lying to questions: response time as a cue to deception. Appl. Cogn. Psychol. 17, 755-774. doi:10.1002/acp.914

Walter, W.G., Cooper, R., Aldridge, V.J., McCallum, W.C., \& Winter, A.L., 1964. Contingent Negative Variation: An Electric Sign of Sensorimotor Association and Expectancy in the Human Brain. Nature 203, 380-384. doi:10.1038/203380a0

Wascher, E., Verleger, R., Jaskowski, P., \& Wauschkuhn, B., 1996. Preparation for action: an ERP study about two tasks provoking variability in response speed. Psychophysiology 33(3), 262-272. doi:10.1111/j.1469-8986.1996.tb00423.x

Wickens, C., Kramer, A., Vanasse, L., \& Donchin, E., 1983. Performance of concurrent tasks: a psychophysiological analysis of the reciprocity of information-processing resources. Science, 221(4615), 1080-1082. doi:10.1126/science.6879207

Wu, H., Hu, X., \& Fu, G, 2009. Does willingness affect the N2-P3 effect of deceptive and honest responses? Neurosci. Lett. 467(2), 63-66. doi:10.1016/j.neulet.2009.10.002 
Yeung, N., \& Cohen, J.D., 2006. The impact of cognitive deficits on conflict monitoring predictable dissociations between the error-related negativity and N2. Psychol. Sci. 17(2), 164-171. doi:10.1111/j.1467-9280.2006.01680.x

Zuckerman, M., DePaulo, B.M., \& Rosenthal, R., 1981. Verbal and nonverbal communication of deception. In: Berkowitz. L. (Ed.), Adv. Exp. Soc. Psychol. 14, Academic Press, New York, pp. 1-57. doi:10.1016/S0065-2601(08)60369-X 


\section{A. Appendix}

\section{A.1. Method}

Preprocessing of the response-locked LRP was identical to preprocessing steps 1-6. Additionally, (7) for the R-locked LRP, a baseline correction was performed (-200 ms to keyword), and epochs were segmented $-1000 \mathrm{~ms} /+200 \mathrm{~ms}$ around the response. Then, trials were averaged for each experimental condition and left and right hand responses separately. For the response-locked LRP, the mean activity during the -300 to $0 \mathrm{~ms}$ interval before the response was calculated and analyzed.

To gain more information on possible differences between conditions in the duration of stimulus processing prior to response activation and the duration of response activation (before the overt response), the onsets of stimulus- and response-locked LRPs were computed. To reduce the impact of high-frequency noise on the onset detection, additional filtering with a high cut-off of $8 \mathrm{~Hz}$ was applied before the LRP onsets were computed. The LRP onsets were computed using the jackknifing method (Miller et al., 1998; Smulders, 2010; Ulrich \& Miller, 2001). The (relative) onset of the LRP was defined as the point in time in which activation exceeded $-0.5 \mu \mathrm{V}$.

\section{A.2. Results}

\section{A.2.1. Response-locked LRP}

The grand average waveforms of the response-locked LRP revealed clear LRPs in all four conditions (Figure A.1.). Visual inspection suggested a slightly larger LRP with a longer interval between LRP onset and overt response in the lie conditions compared to the truth conditions.

\section{- INSERT FIGURE A.1. ABOUT HERE -}

The mean activity for the response-locked LRP in the interval between -300 and 0 was analyzed with a 2 (Deception: truth vs. lie) x 2 (Enactment: enacted vs. intended crime) MANOVA. The analysis revealed a marginally significant main effect of Deception, $F(1,19)$ $=3.74, p=.068, d=0.43,95 \%$ CI $[-0.03,0.89]$, with the LRP in the lie condition being unexpectedly larger compared to the truth condition, and no significant main effect of Enactment, $F(1,19)=0.00, p=.973, d=0.01,95 \%$ CI $[-0.43,0.45]$. There was also no significant interaction effect, $F(1,19)=0.49, p=.493, f=0.16$. 


\section{A.2.2. Onset latencies}

A 2 (Deception: Truth vs. Lie) x 2 (Enactment: enacted vs. intended crime) MANOVA on the onset latencies of the stimulus-locked LRPs revealed no significant main effects of Deception, $F(1,19)=0.03, p=.865, d=0.04$, 95\% CI [-0.40, 0.48] (Truth: $M=$ $349 \mathrm{~ms}, S D=154$ vs. Lie: $M=371 \mathrm{~ms}, S D=516$; after keyword presentation), or Enactment, $F(1,19)=0.12, p=.730, d=0.08,95 \%$ CI $[-0.36,0.52]$ (enacted crime: $M=377 \mathrm{~ms}, S D=$ 98 vs. intended crime: $M=343, S D=450$; after keyword presentation). Also the interaction effect was not significant, $F(1,19)=0.27, p=.609, f=0.12$.

A 2 (Deception: Truth vs. Lie) x 2 (Enactment: enacted vs. intended crime) MANOVA on the onset latencies of the response-locked LRPs revealed no significant main effects of Deception, $F(1,19)=2.22, p=.153, d=0.33$, 95\% CI [-0.12, 0.78] (Truth: $M=-$ $219 \mathrm{~ms}, S D=124$ vs. Lie: $M=-272 \mathrm{~ms}, S D=91$; relative to response), or Enactment, $F(1$, $19)=0.02, p=.897, d=0.03,95 \%$ CI [-0.40, 0.47] (enacted crime: $M=-244 \mathrm{~ms}, S D=80$ vs. intended crime: $M=-248, S D=106$; relative to response). Also the interaction effect was not significant, $F(1,19)=2.04, p=.170, f=0.45$.

Note that in all analyses reported in the appendix, we also explored LRP results at FC3/FC4. Including the LRP at these electrodes in our analyses did not change the pattern of results. 


\section{Figures}

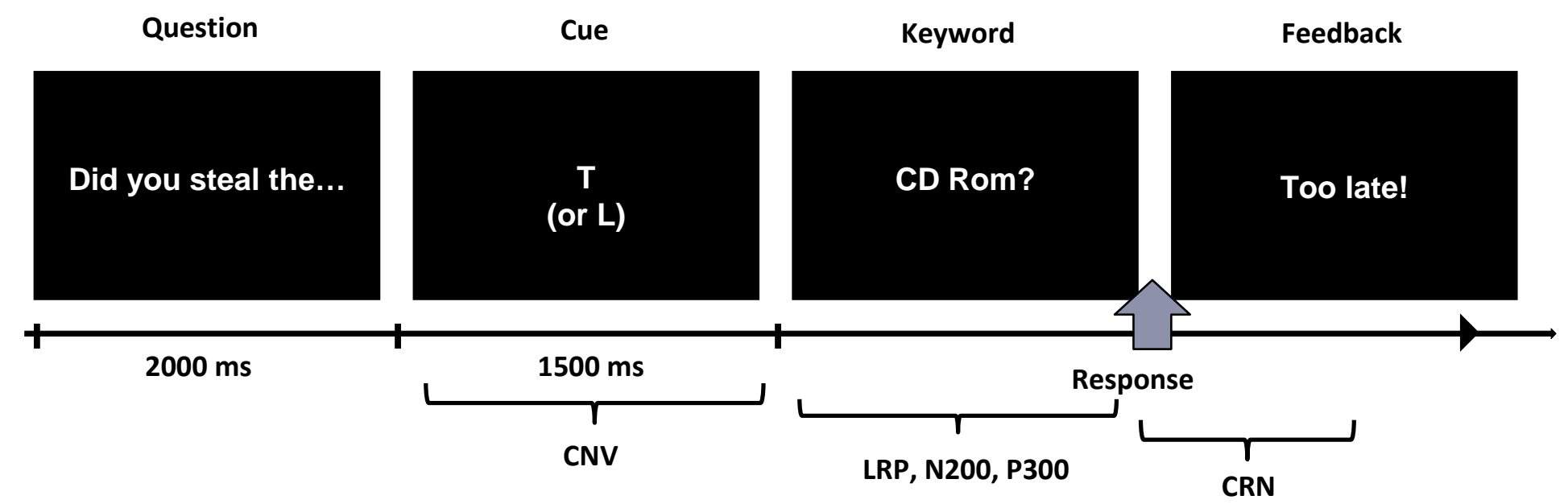

Figure 1. Sheffield Lie Test adapted for the measurement of ERPs. 

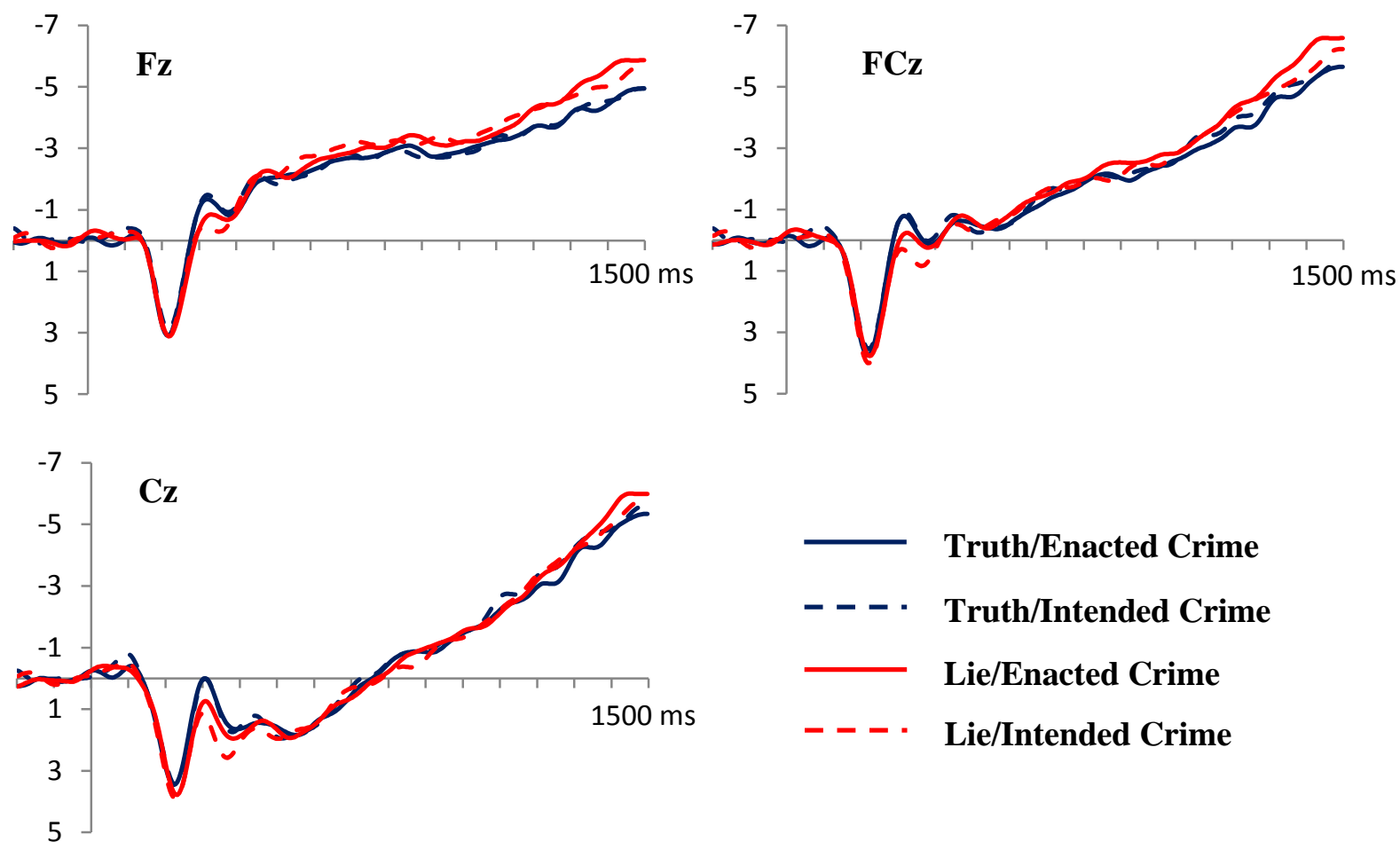

- - - - Lie/Intended Crime

Figure 2. Grand average $\mathrm{CNV}$ waveforms at $\mathrm{Fz}, \mathrm{FCz}$, and $\mathrm{Cz}$ for each of the four experimental conditions. Values at the $\mathrm{y}$-axis represent the activity in $\mu \mathrm{V}$. Values at the $\mathrm{x}$-axis represent the time $(1$ unit $=100 \mathrm{~ms})$. For illustrative purposes, grand averages were additionally filtered with a high cut-off of $8 \mathrm{~Hz}$. 

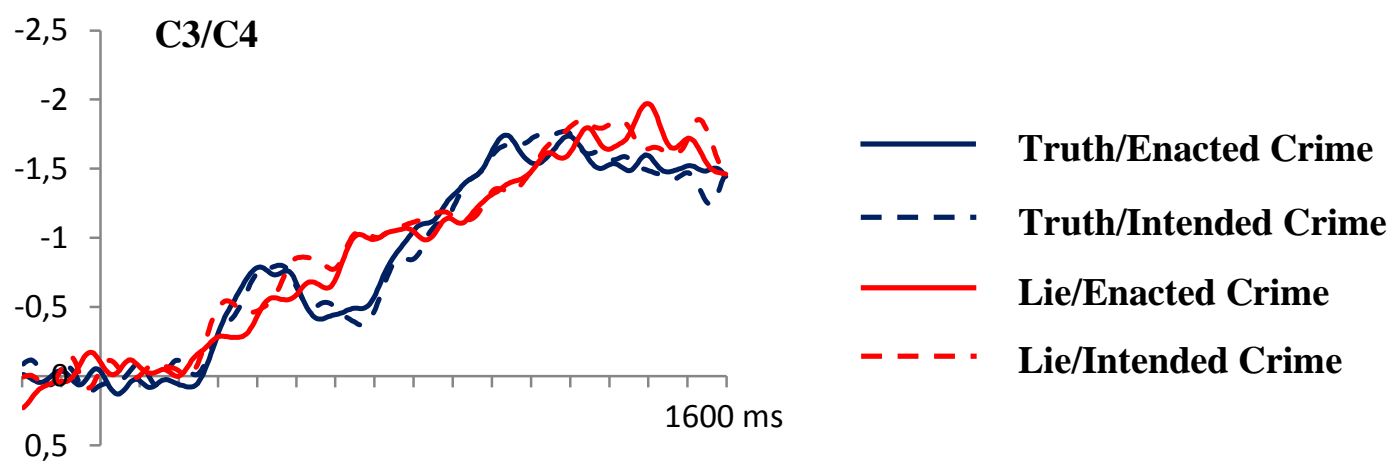

Figure 3. Grand average stimulus-locked LRP waveforms at $\mathrm{C} 3 / \mathrm{C} 4$ for each of the four experimental conditions. Values at the $y$-axis represent the activity in $\mu \mathrm{V}$. Values at the $\mathrm{x}$-axis represent the time $(1$ unit $=100 \mathrm{~ms})$. Note that upward values represent correct response activation and downward values represent incorrect response activation. For illustrative purposes, grand averages were additionally filtered with a high cut-off of $8 \mathrm{~Hz}$. 


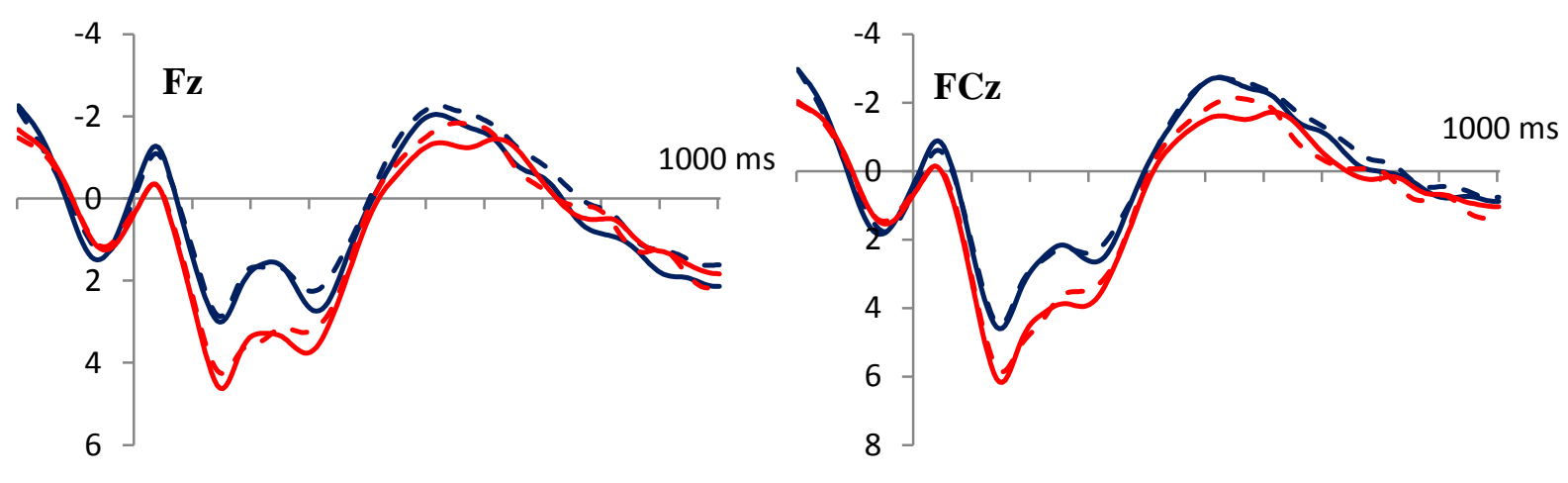

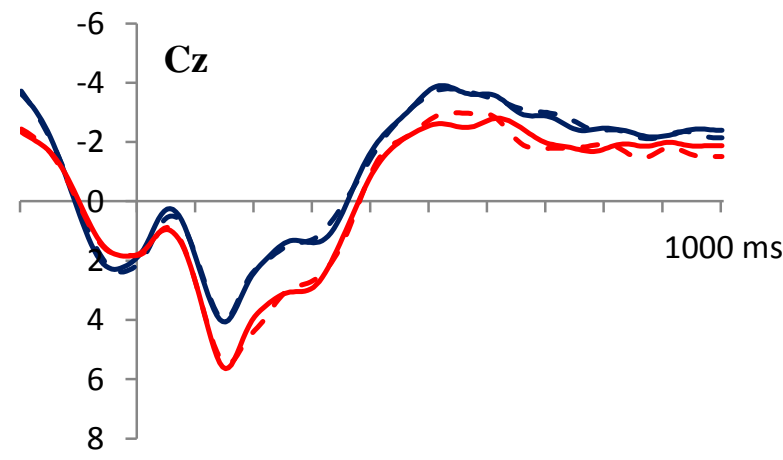

- Truth/Enacted Crime - - - . Truth/Intended Crime

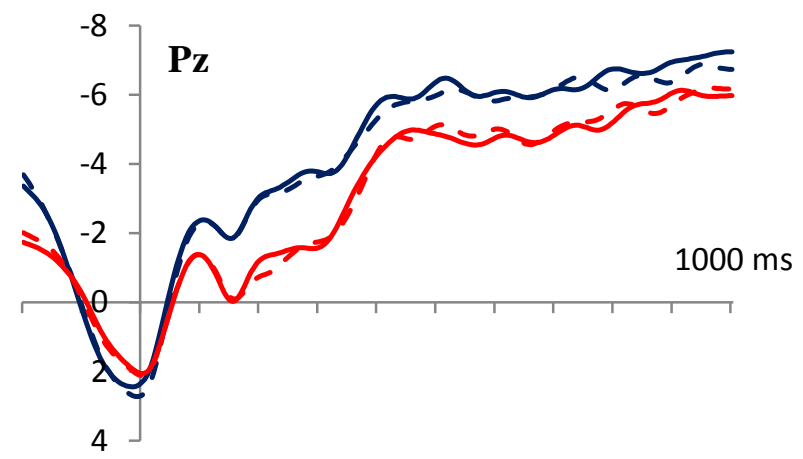

Lie/Enacted Crime - - - - Lie/Intended Crime

Figure 4. Grand average $\mathrm{CRN}$ waveforms at $\mathrm{Fz}, \mathrm{FCz}, \mathrm{Cz}$, and $\mathrm{Pz}$ for each of the four experimental conditions. Values at the $y$-axis represent the activity in $\mu \mathrm{V}$. Values at the $\mathrm{x}$-axis represent the time $(1$ unit $=100 \mathrm{~ms})$. For illustrative purposes, grand averages were additionally filtered with a high cut-off of $8 \mathrm{~Hz}$. 

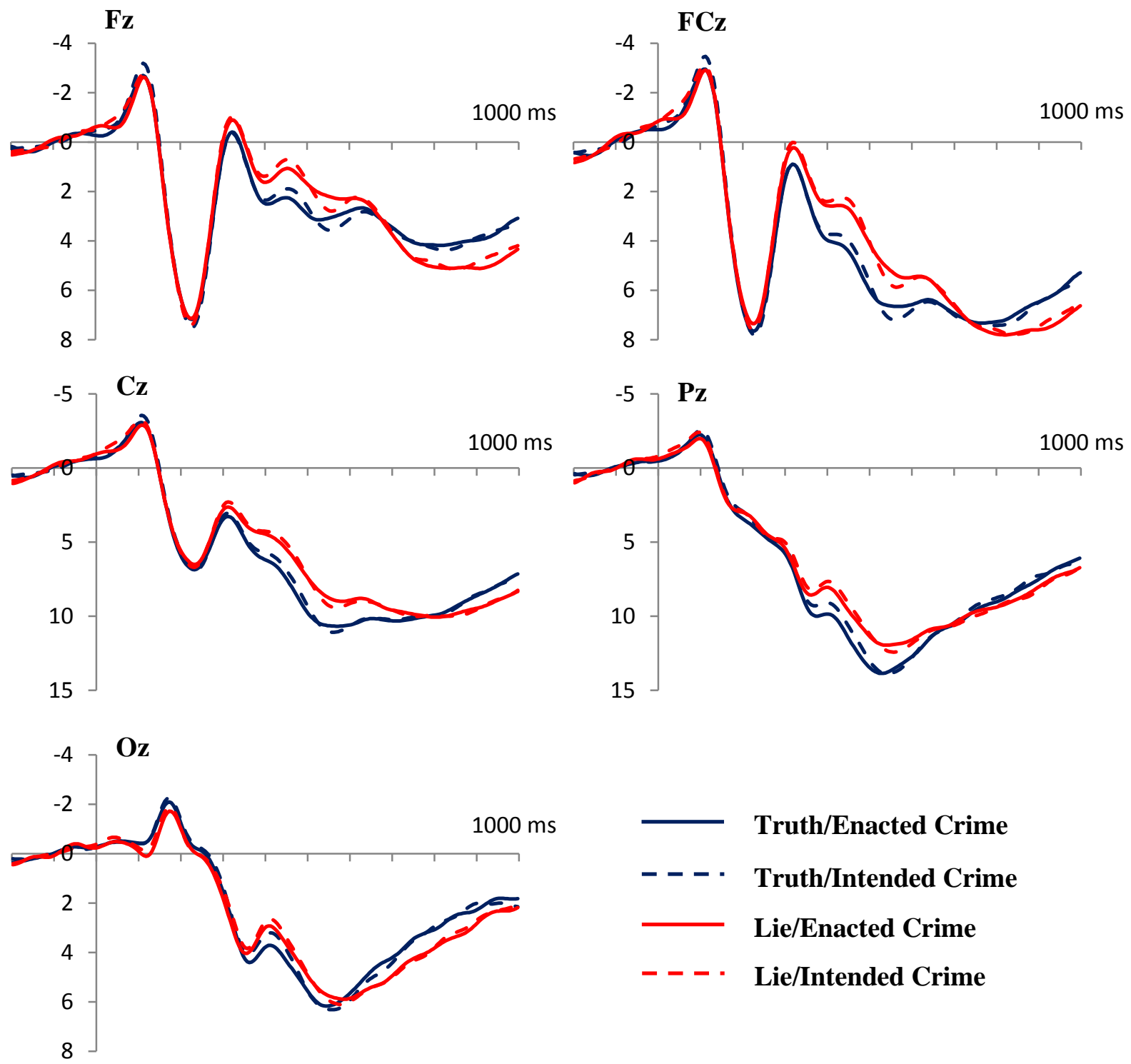

- - - Truth/Intended Crime

Lie/Enacted Crime

- - - Lie/Intended Crime

Figure 5. Grand average N200 and P300 waveforms at Fz, FCz, Cz, Pz, and $\mathrm{Oz}$ for each of the four experimental conditions. Values at the y-axis represent the activity in $\mu \mathrm{V}$. Values at the $\mathrm{x}$-axis represent the time ( 1 unit $=100 \mathrm{~ms})$. For illustrative purposes, grand averages were additionally filtered with a high cut-off of $8 \mathrm{~Hz}$. 


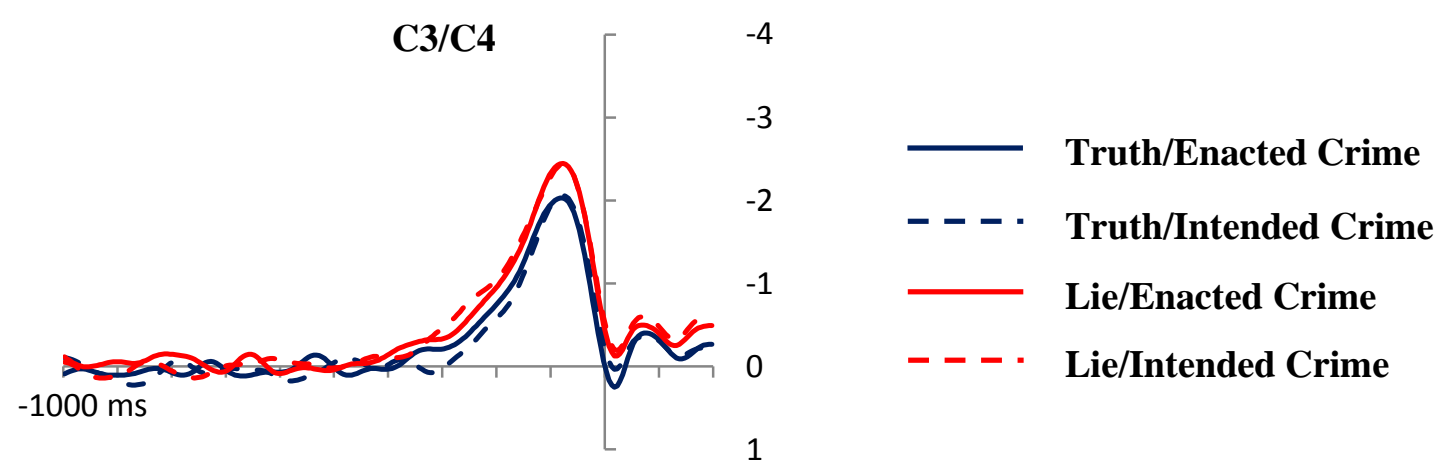

Figure A.1. Grand average response-locked LRP waveforms at C3/C4 and FC3/FC4 for each of the four experimental conditions. Values at the $\mathrm{y}$-axis represent the activity in $\mu \mathrm{V}$. Values at the $\mathrm{x}$-axis represent the time $(1 \mathrm{unit}=100 \mathrm{~ms})$. Note that upward values represent correct response activation and downward values represent incorrect response activation. For illustrative purposes, grand averages were additionally filtered with a high cut-off of $8 \mathrm{~Hz}$. 